\title{
Pulmonary rehabilitation at home
}

Pulmonary rehabilitation programmes are now well established to provide a comprehensive approach to controlling and alleviating symptoms and to optimising the functional capacity of patients with chronic obstructive pulmonary disease (COPD). Recently, pulmonary rehabilitation was defined as "a multidimensional continuum of services directed to persons with pulmonary disease and their families, usually by an interdisciplinary team of specialists, with the goal of achieving and maintaining the individual's maximum level of independence and functioning in the community." The benefits of pulmonary rehabilitation are addressed in many studies. Most of these were carried out in an inpatient or outpatient setting. Only a few studies have investigated the effects of pulmonary rehabilitation at home. ${ }^{2-7}$ This is remarkable as home rehabilitation should be preferred since it is more convenient for the patients; they stay in touch with their families and apply their training in their daily life. Moreover, it can be anticipated that home rehabilitation would be cheaper than inpatient rehabilitation. This leaves some issues open for debate - for example, which is the best programme for home rehabilitation for patients with COPD and what training techniques can or should be included?

Although at first sight this seems contradictory, home rehabilitation for patients with COPD must begin in the hospital with an initial evaluation of the patient's clinical condition by a pulmonary physician. This should include physical examination, lung function tests, exercise tolerance tests (including a maximal exercise test), and a quality of life assessment. Based upon these results the physician decides whether the patient is able to participate in a home rehabilitation programme. Patients with severe hypoxaemia at rest and those who need oxygen during exercise are not appropriate candidates. In addition, most studies have excluded patients with ischaemic heart disease or other associated medical problems. ${ }^{2-7}$

Home rehabilitation can be structured in two ways. Firstly, initial instruction and supervision during the programme takes place at the hospital, after which the patients are regularly supervised by a physiotherapist at an outpatient clinic. $^{257}$ Secondly, home rehabilitation is fully addressed at home with instruction and regular supervision, either by a local physiotherapist ${ }^{4}$ or a multidisciplinary team. ${ }^{36}$ The latter form of home rehabilitation is more convenient for the patients as they do not have to visit the hospital.

Although the type of home rehabilitation may differ, programmes always contain at least some physiotherapy. Frequently used techniques are relaxation exercises, ${ }^{367}$ breathing retraining, ${ }^{367}$ exercise training, ${ }^{2-7}$ inspiratory muscle training, ${ }^{5-7}$ and upper limb training. ${ }^{67}$ Relaxation exercises can be carried out according to Jacobson's technique of progressive muscle relaxation. ${ }^{8}$ Breathing retraining generally consists of pursed lip breathing, expiratory abdominal augmentation, and synchronisation of thoracic and abdominal movements. ${ }^{9}$ Exercise programmes vary from walking exercises ${ }^{5}$ and progressive stair climbing exercises ${ }^{2}$ to walking or stair stepping ${ }^{4}$ or bicycle exercises. ${ }^{367}$ Two recently reported programmes also included upper limb training, in one study ${ }^{6}$ carried out according to the principles of proprioceptive neuromuscular facilitation (PNF). ${ }^{10}$ Finally, inspiratory muscle training has also been practised at home, either by isocapnic hyperventilation training 5 or by target flow inspiratory muscle training (IMT) with an added resistance. ${ }^{6}$

With all these detailed studies investigating the physiological effects of rehabilitation it is remarkable that at present the optimal duration of the different types of daily training is not known. Physiological improvements by exercise training are achieved in patients with only moderate reductions in pulmonary function. In one study endurance/exercise training was carried out for 30-45 minutes a day, 3-5 days a week for eight weeks, ${ }^{11}$ and the patients showed significant decreases of both serum lactate levels and maximal minute ventilation at identical workloads after eight weeks. On the other hand, most patients with COPD and severe airflow obstruction are limited in their exercise capacity because of ventilatory pump failure and are unable to reach their anaerobic threshold. ${ }^{12}$ In these patients target flow IMT was effective in increasing inspiratory muscle function and exercise tolerance when carried out twice a day for 15 minutes at $70 \%$ of maximal inspiratory pressure (PImax). ${ }^{13} \mathrm{~A}$ problem arises when IMT is carried out in a home setting. PImax will increase with training, hence training levels should be adjusted accordingly. Since local physiotherapists do not have the equipment to assess PImax, the patients have to visit the hospital to increase training levels of IMT.

In addition to the physical training, some studies advocated a role for a general practitioner and a nurse. ${ }^{36}$ The task of the general practitioner is to supervise the clinical status and maintenance treatment. The nurse visits the patients at home and gives both patients and family members insight into potential disabilities and handicaps caused by the lung disease. If needed, information can be provided about the disease, strategies for treatment, use of the medication, ways of coping, and the beneficial contribution of a rehabilitation programme. A number of controlled studies have investigated the effects of home rehabilitation in patients with COPD. A thorough comparison between these studies is not possible as all use different elements of training. Nevertheless, all studies found positive effects after home rehabilitation, but in different ways. Patients with chronic bronchitis (mean forced expiratory volume in one second $\left(\mathrm{FEV}_{1}\right)$ of $\left.1.0 \mathrm{l}\right)$ improved their maximal walking distance, general well being, and decreased their breathlessness by unsupervised stair climbing exercises. ${ }^{2}$ More comprehensive training programmes carried out by patients with severe airflow obstruction $\left(\mathrm{FEV}_{1}\right.$ of $\left.0 \cdot 8-1 \cdot 11\right)$ showed an improved maximal workload during a bicycle ergometer test, ${ }^{34614}$ a decrease in dyspnoea, ${ }^{36714}$ and positive effects of inspiratory muscle training. ${ }^{56}$ Both isocapnic hyperventilation training and target flow IMT $^{15}$ were successful in increasing ventilatory muscle endurance. Although in the latter study the training level of Pimax was not adjusted during the 12 weeks of training, a significant difference developed between the training and control groups. ${ }^{15}$ Finally, rehabilitation at home was successful in improving the quality of life compared with a control group who did not receive rehabilitation. ${ }^{6}$ Although an improved quality of life has been mentioned in many studies of pulmonary rehabilitation, our group was the first to show that home rehabilitation improves quality of life, assessed by a valid questionnaire. We also showed that an improved quality of life was not correlated with an improved exercise tolerance. ${ }^{6}$ Thus, we can conclude that home rehabilitation is successful in improving both physical performance and 
quality of life. These positive effects must be interpreted as short term effects because all the above studies had a maximal duration of 18 weeks.

The effects of home rehabilitation over an 18 month period have recently been assessed. Rehabilitation at home supervised by a multidisciplinary team for three months continued by physiotherapy once monthly improved quality of life over 18 months, while the exercise tolerance in the rehabilitation group did not change. ${ }^{16}$ Moreover, the control group who did not receive any rehabilitation during the 18 months showed a significant decrease in both walking distance and maximal workload during bicycle ergometer tests. These results show that the change in quality of life is not related to the change in exercise tolerance, and that both parameters must be measured separately during rehabilitation.

Apart from an improved exercise tolerance and quality of life, an important question is whether home rehabilitation is effective in reducing the costs of medical care for a patient with COPD. Campbell Haggerty et al showed that home care (nursing visits and physiotherapy) was successful in reducing the number of hospital admissions and costs. ${ }^{17}$ On the other hand, a study by Bergner et $a l^{18}$ compared the effects of standard home care (care from regular home care nurses), specialised home care (care from specialised home care nurses), and standard office care (receiving care whenever they needed but no home care). They found that costs were higher in both home care groups, while no differences in functional ability in daily activities and psychosocial and mental health were found. The different outcomes may be explained by the fact that different patient groups were included. Bergner included all patients with $\mathrm{COPD}^{18}$ while Campbell Haggerty included only those with COPD who were frequently admitted to hospital. ${ }^{17}$ In addition, in the latter study patients received physiotherapy while in the study by Bergner et al no structured physiotherapy was given.

Based on current knowledge, home rehabilitation provides excellent value in the management of patients with COPD. It improves both physical performance and quality of life, certainly for three months (no studies have looked much beyond this). Taking these positive short term effects for granted, further long term home rehabilitation programmes should now investigate (1) the kind of training that should be performed to maintain the initial improvements, and (2) what the optimal frequency of follow up treatment should be. In addition, cost effectiveness should be included as an outcome parameter.

Rehabilitation Centre Beatrixoord,

PJ WIJKSTRA

9751 ND Haren and

Department of Pulmonary Diseases,

University Hospital,

Groningen, The Netherlands

1 NIH Workshop Summary. Pulmonary rehabilitation research. Am $\mathcal{f}$ Respir Crit Care Med 1994;149:825-33.

2 McGavin CR, Gupta SP, Lloyd EL, McHardy JR. Physical rehabilitation for the chronic bronchitic: results of a controlled trial of exercises in the home. Thorax 1977;32:307-11.

3 Strijbos JH, Koëter GH, Meinesz AF. Home care rehabilitation and perception of dyspnea in chronic obstructive pulmonary disease (COPD) patients. Chest 1990;97:109s-10s.

4 Busch A, McClements J. Effects of a supervised home exercise program on patients with severe COPD. Phys Ther 1988;69:469-74.

5 Ries AL, Moser KM. Comparison of isocapnic hyperventilation and walking exercise training at home in pulmonary rehabilitation. Chest 1986;90: 285-9.

6 Wijkstra PJ, van Altena R, Kraan J, Otten V, Postma DS, Koëter GH Quality of life in patients with chronic obstructive pulmonary disease improves after rehabilitation at home. Eur Respir f 1994;7:269-73.

7 Reardon J, Awad E, Normandin E, Vale F, Clark B, ZuWallack RL. The effect of comprehensive pulmonary rehabilitation on dyspnea. Chest 1994, 105:1046-52.

8 Jerman A, Campbell Haggerty M. Relaxation and biofeedback: coping skills training. In: Casaburi R, Petty TL, eds. Principles and practice of pulmonary rehabilitation. Philadelphia: WB Saunders, 1993:366-81.

9 Casciari RJ, Firshter RD, Harrison A, Morrison JT, Blackburn C, Wilson AF. Effects of breathing retraining in patients with COPD. Chest 1981; AF. Effect

10 Ries AL, Ellis B, Hawkins RW. Upper extremity exercise training in chronic obstructive pulmonary disease. Chest 1988;93:688-92.

11 Casaburi R, Patessio A, Ioli F, Zanaboni S, Donner CF, Wasserman K. Reduction in exercise lactic acidosis and ventilation as a result of exercise training in patients with obstructive lung disease. Am Rev Respir Dis 1991, 143:9-18.

12 Casaburi R, Wasserman K. Exercise training in pulmonary rehabilitation. $N$ Engl F Med 1986;314:1509-11.

13 Dekhuijzen PNR, Folgering HTM, Van Herwaarden CLM. Target-flow inspiratory muscle training during pulmonary rehabilitation in patients with COPD. Chest 1991;99:128-33.

14 Wijkstra PJ, van der Mark ThW, Kraan J, van Altena R, Koeter GH, Postma DS. Effects of home rehabilitation on physical performance in patients with chronic obstructive pulmonary disease. Eur Respir F 1995; (in press)

15 Wijkstra PJ, Kraan J, van Altena R, van der Mark ThW, Gimeno F, Postma Wijkstra PJ, Kraan J, van Altena R, van der Mark ThW, Gimeno F, Postma
DS, et al. Maximal inspiratory pressure and endurance capacity of the inspiratory muscles improve after rehabilitation at home. Eur Respir $\mathcal{F}$ 1993;6(Suppl 17): 311s.

16 Wijkstra PJ, TenVergert EM, van Altena R, Otten V, Kraan J, Postma DS et al. Long term effects of rehabilitation at home on quality of life and exercise tolerance in patients with chronic obstructive pulmonary disease. Thorax 1995;50:824-8.

17 Campbell Haggerty M, Stockdale-Woolley R, and Nair S. Respi-Care. An innovative home care program for the patient with chronic obstructive pulmonary disease. Chest 1991;100:607-12.

18 Bergner M, Hudson L, Conrad D, Patmont CM, McDonald GJ, Perrin $\mathrm{EB}$, et al. The cost and efficacy of home care for patients with chronic lung disease. Medical Care 1988;26:566-79. 